\title{
CADEIAS PRODUTIVAS DOS FRUTOS NATIVOS DO CERRADO: ESTUDOS DE CASO SOBRE 0 \\ AGROEXTRATIVISMO NO \\ VALE DO RIO URUCUIA EM MINAS GERAIS E NO SUL
}

Productive chains of the Cerrado's native fruits: case studies on agroextractivism in the Vale do Rio Urucuia in Minas Gerais and the Sul Maranhense

Tayline Walverde Bispo

Stéphane Guéneau

Camila Lago Braga

Cristiane Cavalcante Lima 


\title{
CADEIAS PRODUTIVAS DOS FRUTOS NATIVOS DO CERRADO: ESTUDOS DE CASO SOBRE O AGROEXTRATIVISMO NO VALE DO RIO URUCUIA EM MINAS GERAIS E NO SUL MARANHENSE
}

\author{
Productive chains of the Cerrado's native fruits: case studies on agroextractivism in \\ the Vale do Rio Urucuia in Minas Gerais and the Sul Maranhense
}

\author{
Tayline Walverde Bispo \\ Stéphane Guéneau \\ Camila Lago Braga \\ Cristiane Cavalcante Lima
}

\section{Grupo de Trabalho (GT): GT7. Desenvolvimento rural, territorial e regional}

\begin{abstract}
Resumo Este artigo tem por objetivo analisar as cadeias produtivas de frutos nativos do Cerrado, com foco na contribuição desses frutos para o incremento de renda das populações agroextrativistas. A metodologia baseou-se na realização de pesquisas de campo nos municípios de São Raimundo das Mangabeiras e Carolina, no Maranhão, e no município de Arinos, em Minas Gerais. Para melhor compreensão da organização e do funcionamento das cadeias produtivas, foram entrevistadas 40 pessoas, entre agroextrativistas, representantes sindicais e representantes de cooperativas. Também foram realizadas observações em reuniões, feiras e visitas em propriedades rurais entre os anos de 2017 e 2019. As principais cadeias produtivas identificadas foram a do baru, do pequi, do bacuri e do cajá, selecionadas por possuírem dinâmicas próprias de produção e comercialização, com grande relevância para a economia local das regiões estudadas. Mediante uma análise de cadeia produtiva de Produtos Florestais não Madeireiros (PFNM), verificou-se o potencial de diferentes frutos nativos do Cerrado. Os resultados obtidos comprovam a relevância das cadeias produtivas e permitem concluir que, quanto mais organizada e estruturada estiver a cadeia, maiores serão os benefícios para os agroextrativistas, influenciando positivamente na qualidade de vida desse segmento.
\end{abstract}

Palavras-chave: Agroextrativismo. Cerrado. Desenvolvimento Rural.

Abstract: This article aims to analyze the productive chains of native fruits of Cerrado with a view to their contribution to the increase of income of the agroextractive populations and to the local rural development. From the methodological procedures, field research was carried out in the South Maranhão region and in the Urucuia River Valley, in Minas Gerais. For a better understanding of the organization and functioning of the production chains, 40 people were interviewed, including agroextractivists, union representatives and cooperatives. Observations were also made at meetings, fairs and visits to rural properties between the years of 2017 and 2019. The main productive chains identified were baru, pequi, bacuri and cajá, selected for having their own production and commercialization dynamics, with great relevance for local economy of the examined regions. By analyzing the production chain of non-timber forest products (NTFPs), the potential of different native fruits of the Cerrado from regions of Maranhão and Minas Gerais was verified, proving, through the results obtained, the relevance of the production chains, realizing that the more organized and structured the chain, the greater the benefits to agroextractivists, positively influencing the quality of life of this segment.

Keywords: Agroextractivism. Brazilian Cerrado. Rural Development. 


\section{INTRODUÇÃO}

O território brasileiro possui uma grande riqueza em biodiversidade (FORZZA et al., 2010). Entretanto, desde o início da colonização europeia, o Brasil tem sido alvo da dilapidação dos recursos naturais. O próprio nome do país é derivado de um produto do extrativismo vegetal indiscriminado, o pau-brasil (Paubrasilia echinata). Mais recentemente, a degradação da natureza ocorre devido à expansão e à poluição dos grandes centros urbanos, à agricultura extensiva de grande porte, à exploração mineral e florestal, dentre outros fatores.

As problemáticas citadas têm atingido as populações brasileiras, especialmente aquelas residentes em áreas rurais. É necessário melhorar a qualidade de vida dessas comunidades que estão em contato direto com o meio ambiente, pois têm sido cada vez mais pressionadas pelas mudanças constantes provocadas na natureza. Em meio a esse contexto, o agroextrativismo se mostra como uma alternativa de desenvolvimento para as populações que vivem no meio rural, uma vez que se fundamenta na combinação da atividade do extrativismo de Produtos Florestais não Madeireiros (PFNMs), na produção agrícola e na criação de animais (BRASIL, 2006). Assim, é possível que o indivíduo se mantenha no meio rural, de modo a reduzir o impacto nos recursos naturais e obter renda e alimento a partir dos frutos nativos disponíveis na natureza. De acordo com Dutra e Souza (2017, p. 112), os resultados positivos decorrentes das práticas agroextrativistas são "o apoio à permanência da população no campo, a geração e distribuição de renda através $[s i c]$ da produção agropecuária sustentável aliada à utilização consciente da biodiversidade, o que, ao mesmo tempo, permite a conservação dos ecossistemas".

Os frutos nativos do Cerrado são considerados Produtos Florestais não Madeireiros porque podem ser extraídos da floresta com possibilidade de manejo sustentável. Entre eles, encontram-se óleos, resinas, bambus, fibras, plantas medicinais, látex e frutas. Também podem ser incluídos os recursos animais e ainda os benefícios ou serviços indiretos advindos da manutenção da cobertura florestal, como água, conservação dos solos e condições climáticas (ABRANTES, 2002). Utilizou-se, então, a análise das cadeias produtivas de PFNMs para caracterizar o agroextrativismo dos frutos nativos do Cerrado. Entende-se que a análise de cadeia produtiva é uma mesoanálise, visto que permite a interpretação dos mecanismos e das interações dos fatores produtivos, organizações, atores e instituições relacionados a determinado produto (GRIFFON, 1994; LANÇON; TEMPLE; BIÉNABE, 2017).

Diante desse quadro, o objetivo deste artigo ${ }^{1}$ foi analisar as cadeias produtivas de frutos nativos do Cerrado, com foco na contribuição desses frutos para o incremento de renda das populações agroextrativistas, nos municípios de São Raimundo das Mangabeiras e Carolina, no Maranhão, e no município de Arinos, em Minas Gerais. Enfatizou-se o agroextrativismo no Cerrado, por ser um dos biomas brasileiros mais impactados pelas atividades humanas, ao mesmo tempo em que possui grande importância socioeconômica para as populações locais. Destacam-se as cadeias produtivas do baru (Dipteryx alata Vog.), pequi (Caryocar brasiliense), bacuri (Platonia insignis) e cajá (Spondias mombin L.), por possuírem cadeias diferentes, indo do mais complexo (caso do baru, com comercialização que abrange o mercado internacional) ao mais simples (como o cajá, que atende, principalmente, os mercados institucionais e as populações locais).

\footnotetext{
${ }^{1}$ Este artigo é resultado do Projeto Sociobiocerrado (Inovações Sociotécnicas e Institucionais para a Conservação e Valorização do Bioma Cerrado), financiado pela Fondation Agropolis e pela Coordenação de Aperfeiçoamento de Pessoal de Nível Superior (CAPES), bem como de uma parceria entre o Centre de Cooperation International en Recherche Agronomique pour le Développment (CIRAD) e o Centro de Desenvolvimento Sustentável (CDS) da Universidade de Brasília (UnB). Resulta também da tese de doutorado de Bispo (2020), que teve como objetivo analisar as mudanças nas cadeias produtivas dos frutos do Cerrado e a evolução dos mercados, com vistas à contribuição do agroextrativismo para a conservação do bioma e para o desenvolvimento rural sustentável das populações.
} 
A metodologia caracteriza-se como pesquisa social aplicada. Construiu-se um panorama das cadeias produtivas dos frutos do bioma Cerrado. Foram escolhidas duas regiões distintas para a realização da pesquisa de campo: a região Sul Maranhense e a do Vale do Rio Urucuia, em Minas Gerais. Essas duas regiões foram selecionadas em razão da presença do agroextrativismo coletivo de produtos provenientes do Cerrado. No Maranhão, as pesquisas foram realizadas em dois municípios, Carolina e São Raimundo das Mangabeiras; e, em Minas Gerais, no município de Arinos. Conduziram-se 40 entrevistas com agroextrativistas, representantes sindicais e agentes públicos municipais e estaduais. Também se recorreu à participação em reuniões das organizações e com autoridades políticas estaduais e locais. A pesquisa de campo foi realizada entre os anos de 2017 e 2019, com rodadas de entrevistas, visitas às organizações e cooperativas dos agroextrativistas e às propriedades destes nas duas regiões.

A seguir, organiza-se o artigo em cinco seções, contando com a presente introdução. Na seção 2, discutem-se os conceitos de cadeias produtivas. Na seção 3, caracteriza-se brevemente o agroextrativismo no Cerrado. $\mathrm{Na}$ seção 4, realiza-se uma análise das principais cadeias produtivas de frutos nativos do Sul Maranhense e do Vale do Rio Urucuia. Por fim, na seção 5, apresentam-se as principais conclusões do trabalho.

\section{CADEIAS PRODUTIVAS: ESTADO DA ARTE}

A literatura sobre cadeias produtivas inspira-se muito na escola francesa que trata do conceito de filière, termo francês que significa "todos os passos para alcançar um resultado". Esse conceito é, frequentemente, utilizado na literatura vinculada à economia agrícola e agroalimentar, sendo apresentado como uma mesoanálise, que tem por fundamento o reconhecimento da existência de níveis intermediários entre as unidades de base (empresas, indústrias) e a economia global. Esses níveis intermediários (reagrupamentos de agentes individuais ou de unidades de base) constituem subconjuntos do sistema produtivo inseridos na economia global e são representados pelas cadeias produtivas (GRIFFON, 1994).

A abordagem francesa é um conjunto abrangente de estudos com a característica comum de usar a cadeia de atividades e trocas como uma ferramenta, o que delimita o escopo da análise. Refere-se, portanto, a um campo de estudo de nível meso, em vez de uma teoria e, também, um mecanismo prático de análise para uso em pesquisas aplicadas (RAIKES; JENSEN; PONTE, 2000). A filière é definida como a união da sequência técnica, logística e comercial necessária para a produção e distribuição de alimentos ou produtos agroindustriais por meio da produção para o consumo (LANÇON; TEMPLE; BIÉNABE, 2017).

Na prática, a análise de filière pode estar centrada em uma série de aspectos, entre eles: um produto ou grupo de produtos relacionados; uma tecnologia ou um grupo de tecnologias; um processo de controle estratégico comercial ou financeiro; e um espaço fortemente integrado. As cadeias produtivas ou mesossistemas desempenham uma mediação entre as unidades de base e a economia global. Constituem uma estrutura não neutra da realidade econômica, porque mudam o comportamento, organizam as relações e condicionam as estratégias. As unidades de base pertencem a um ou vários mesossistemas, onde são constituídos para os mesmos backgrounds sociais, econômicos e técnicos de referência, de reconhecimento e de credibilidade (GRIFFON, 1994).

As cadeias produtivas possuem uma sequência de operações de bens ou serviços em que há uma interdependência e hierarquia entre os agentes (KRAG et al., 2017). Para Morvan (1988), existem três séries de elementos relacionados às cadeias produtivas: i) sucessão de operações de transformação dissociáveis, capazes de serem separadas e ligadas em uma sequência técnica; ii) conjunto de relações comerciais e financeiras que perpassam todos os estados de transformação, desde os fornecedores até os clientes; e iii) conjunto de ações

IGepec, Toledo, V.25, p.133-152, 2021. Edição Especial:58Congresso da SOBER 
econômicas que governam a valoração dos meios de produção e dão segurança ao funcionamento das operações.

Castro, Lima e Cristo (2002) apontam que a análise das cadeias produtivas nasce do enfoque sistêmico. A Teoria Geral dos Sistemas demonstra que há uma tendência à integração das ciências sociais e naturais, sendo que esse pressuposto é validado por estudos iniciais de análise de cadeia produtiva que permitiram a compreensão dos complexos macroprocessos de produção, avaliação de desempenho dos sistemas, determinação de gargalos, oportunidades não exploradas, processos produtivos, gerenciais e tecnológicos.

De acordo com Batalha (1995), a análise da cadeia produtiva está situada entre dois campos da economia: a microeconomia e a macroeconomia. No entanto, a cadeia também deve ser vista como um sistema aberto, ou seja, existe uma interação entre a organização e o ambiente onde ela está inserida. Pode-se dividir uma cadeia em três macrossegmentos: produção de matérias-primas, industrialização e comercialização. Essa divisão, muitas vezes, não é clara e pode variar de acordo com o produto ou o tipo de análise que será feita.

Para Begnis, Estivalete e Pedrozo (2007), cada cadeia produtiva tem sua história, e os resultados dos inter-relacionamentos vão além das transações econômicas. Existem relações técnicas, econômicas, sociais e políticas, em que varia o comprometimento dos participantes, determinando sua estrutura e sua coordenação. No caso específico do Brasil, as cadeias produtivas do agroextrativismo contemplam os produtos advindos da natureza com o saber da população rural.

\section{AGROEXTRATIVISMO DO CERRADO}

O agroextrativismo é praticado por agricultores familiares que têm a atividade extrativa como complementar à produção agropecuária e vice-versa. Nesse sentido, ele une as atividades agricultura, pecuária de pequeno porte e extrativismo, que são feitas de forma concomitante (BISPO, 2014). O extrativismo pode ser definido como "a exploração dos recursos naturais (animal e vegetal) em ecossistemas diversos e voltados para diferentes mercados" (MOTA et al., 2014, p. 191) e incorpora também o extrativismo mineral.

Nogueira e Fleischer (2005) afirmam que o agroextrativismo é uma categoria que teve origem no movimento social amazônico. Diferentemente da prática apenas extrativa, principalmente de PFNMs, trata-se de um termo mais abrangente que inclui todo o sistema familiar de produção, tanto referente à agricultura quanto à criação de animais.

De acordo com Carrazza (2009), o agroextrativismo é uma atividade familiar que, com a utilização de tecnologia apropriada, une a coleta dos recursos da biodiversidade nativa com a produção agropecuária, destinando parte dessa produção ao autoconsumo e parte para o mercado. Consequentemente, consegue aliar a conservação ambiental à inclusão social e à qualidade de vida das populações envolvidas. De acordo com a Instrução Normativa Conjunta n. ${ }^{\circ}$ 17, de maio de 2009, dos Ministérios da Agricultura, Pecuária e Abastecimento e do Meio Ambiente, o agroextrativismo: ${ }^{2}$

[...] é a combinação de atividades extrativas com técnicas de cultivo, criação e beneficiamento; é orientado para a diversificação, consórcio de espécies, imitação da estrutura e dos padrões do ambiente natural, e uso de técnicas geralmente desenvolvidas a partir dos saberes e práticas tradicionais, do conhecimento dos ecossistemas e das condições ecológicas regionais (BRASIL, 2009, não paginado).

\footnotetext{
${ }^{2}$ Além disso, na mesma Instrução Normativa, é considerado extrativista tanto aquele que pratica extrativismo quanto o que pratica agroextrativismo.
} 
Verifica-se que os aspectos constitutivos do conceito de agroextrativismo extrapolam os fatores puramente econômicos do processo. Estes, embora importantes, devem ceder espaço a outras dimensões, como a social, ambiental e cultural, haja vista a necessidade de discutir aspectos de incremento de renda e reprodução social dos agricultores familiares. A normativa sinaliza a importância do agroextrativismo para a valorização dos saberes locais e das práticas tradicionais, bem como o potencial dessa prática para a sustentabilidade ambiental.

Apesar de autores ligados ao movimento ambientalista terem a visão da sustentabilidade associada ao agroextrativismo (CARRAZZA, 2009; NOGUEIRA; FLEISCHER, 2005), outros vêm problematizando esta afirmação, principalmente, em relação às questões ambientais. Arnold e Perez (2001) afirmam que as contribuições dos PFNMs como meio de subsistência e o fato de serem menos destrutivos do que a extração de madeira incentivaram a crença de que tais produtos poderiam contribuir para o desenvolvimento e para a conservação, daí a expansão do uso comercial. Todavia, na prática, a natureza seletiva da demanda do mercado e a distribuição desigual dos recursos de valor nas florestas fazem com que o recurso seja alterado e degradado. As forças de mercado podem exercer mecanismos de controle local, assim como os interesses conflitantes daqueles que usam os recursos florestais para subsistência e geração de renda podem resultar na desvantagem dos agroextrativistas mais pobres, à medida que a comercialização dos PFNMs é intensificada.

Em termos de inserção no mercado nacional, os produtos da Amazônia se diferem daqueles do Cerrado. Enquanto que os primeiros, desde o início das explorações, atingem o mercado internacional como as "drogas do sertão"3 (HOMMA, 2012; GOMES, 2018; RAVENA; MARIN, 2013), os produtos do Cerrado são consumidos localmente, como é o caso do pequi, do araçá, das plantas medicinais e da madeira. Essa diferença destaca a importância dos frutos nativos do Cerrado tanto para o autoconsumo quanto para o acesso a mercados e a geração de renda das populações locais.

\section{ANÁLISE DAS PRINCIPAIS CADEIAS PRODUTIVAS DE FRUTOS NATIVOS DO VALE DO RIO URUCUIA EM MINAS GERAIS E DO SUL MARANHENSE}

As pesquisas de campo que resultaram no mapeamento e na análise das cadeias produtivas dos frutos nativos do Cerrado foram realizadas no Sul Maranhense (municípios de São Raimundo das Mangabeiras e Carolina), e no Vale do Rio Urucuia (município de Arinos, em Minas Gerais). O Sul Maranhense é uma área de expansão da produção agrícola de grande porte, com cultivo, principalmente, de commodities como soja (Glycine max), milho (Zea mays) e cana-de-açúcar (Saccharum officinarum), porém com a presença de agricultores familiares tradicionais e assentamentos de reforma agrária. O Vale do Rio Urucuia é uma região de ocupação antiga de pequenos produtores rurais, mas que teve sua vegetação original muito impactada pela produção ilegal de carvão vegetal. Atualmente, faz parte de projetos de valorização da biodiversidade e do extrativismo sustentável de frutos nativos. $\mathrm{O}$ agroextrativismo tem alguns produtos que se destacam, apesar de uma imensa variedade de frutos nativos.

Os entrevistados do sul do Maranhão listaram quinze diferentes espécies de frutos nativos: bacaba (Oenocarpus bacaba), bacuri (Platonia insignis), buriti (Mauritia flexuosa), buritirana (Mauritiella armata), cajá (Spondias mombin), caju (Anacardium occidentale), cajuí (Anacardium nanum), coco babaçu (Attalea speciosa), coco macaúba (Acrocomia aculeata), cupuaçu (Theobroma grandiflorum), juçara (Euterpe edulis), mangaba (Hancornia speciosa),

\footnotetext{
${ }^{3}$ Drogas do Sertão são produtos nativos que eram extraídos da Floresta Amazônica na época do Brasil Colonial e direcionados para o mercado europeu, por exemplo o guaraná (Paullinia cupana), o cacau (Theobroma cacao) e o urucum (Bixa orellana).
} 
murici (Byrsonima crassifolia), pequi (Caryocar brasiliense ou Caryocar villosum (Aubl.) Pers. Caryocaraceae) e pitomba (Talisia esculenta). Os mais coletados são o buriti e o pequi, seguidos por bacuri, bacaba, juçara e cajá.

No Vale do Rio Urucuia, alguns frutos coletados diferenciam-se dos do Maranhão. A proximidade do Vale com a capital do país faz com que grande parte da produção seja direcionada para esse mercado. Os frutos mencionados pelos agroextrativistas foram araçá (Psidium cattleianum), araticum (Annona crassiflora), baru (Dipteryx alata), buriti (Mauritia flexuosa), cagaita (Eugenia dysenterica), coco macaúba (Acrocomia aculeata), coquinho azedo (Butia capitata), jatobá (Hymenaea Sp.), mangaba (Hancornia speciosa) e pequi (Caryocar brasiliense). Os frutos mais significativos da região são o baru, em primeiro lugar, e o pequi, em segundo lugar. Existe um diferencial no extrativismo em Minas: com exceção do pequi, os produtos são mais direcionados para o mercado, e o autoconsumo é pouco significativo.

Não obstante a variedade e a disponibilidade na natureza, a maioria dos frutos nativos não compõe a dieta dos entrevistados. A cagaita (Eugenia dysenterica), por exemplo, é um fruto que se perde; alguns entrevistados perguntaram inclusive se há quem a coma. Os frutos do Cerrado possuem uma característica bem peculiar: têm sabor e cheiro muito fortes, por isso nem todos são bem aceitos para consumo generalizado. Os agroextrativistas produzem outros frutos, como abacaxi (Ananas comosus), manga (Mangifera indica), acerola (Malpighia emarginata) e goiaba (Psidium guajava), os quais são autoconsumidos e também comercializados, por meio das cooperativas locais.

Considerando a importância do baru, do pequi, do bacuri e do cajá nas regiões estudadas, serão detalhadas, na sequência, as principais características dos frutos e a organização das respectivas cadeias produtivas.

\subsection{A CADEIA DO BARU NO VALE DO RIO URUCUIA: DE ALIMENTO PARA GADO AO MERCADO INTERNACIONAL}

Com nome científico Dipteryx alata Vog., o baru é uma leguminosa de ocorrência no Cerrado. Possui vários nomes populares, como barujó, baruzeiro, baruí, coco-feijão, cumaru e pau-cumaru, bem como diversos aproveitamentos. Seus frutos possuem uma polpa farinácea e nutritiva, utilizada para alimentação animal, a castanha tem alto teor proteico e capacidade para produção de óleo e a madeira é de alta densidade e durabilidade (VERA; SOUZA, 2009).

Atualmente, a castanha torrada é o produto mais consumido e conhecido advindo do baru, contudo existem outras pesquisas direcionadas para a utilização da polpa e da casca. Rocha e Cardoso Santiago (2009) desenvolveram pães integrais com a farinha da polpa, o que possibilitou um acréscimo de nutrientes no alimento processado. Pesquisas desse tipo são importantes, porque a casca ainda é tida como resíduo, mesmo com o reconhecimento do potencial nutritivo que possui.

Na região estudada em Minas Gerais, o baru era utilizado somente como alimento para gado bovino. Entretanto, alguns fazendeiros acreditam que o gado não pode comer muito baru, porque pode provocar mal-estar ou até a morte do animal, em virtude de uma intoxicação alimentar. Antes de ter valor comercial mais alto, muitos proprietários de fazendas chamavam os catadores de baru para realizar a coleta, de modo que o gado não comesse uma quantidade muito grande. Outro ponto relevante em relação às fazendas de gado é que, nos pastos, quase toda a vegetação foi retirada, permanecendo apenas os pés de baru e de pequi. Para os entrevistados, o baru não faz parte da tradição alimentar da região. Na verdade, existia muito preconceito em relação à castanha, diziam que ela poderia causar coceira e dor de barriga nas pessoas.

A cadeia produtiva do baru está em transformação. Em um estudo feito no ano de 2013 por Bispo (2014), foi demonstrado que havia o extrativismo do baru na região, onde os

IGepec, Toledo, V.25, p.133-152, 2021. Edição Especial:58Congresso da SOBER 
principais compradores eram a cooperativa do município de Arinos e vários atravessadores, principalmente de Brasília. A maioria dos agroextrativistas preferia vender o produto para os atravessadores, em função de o preço ser de dois a quatro reais mais alto que na cooperativa e porque o pagamento era feito à vista, diferentemente da cooperativa, que tinha um prazo de quase trinta dias para o pagamento.

Atualmente, o baru tornou-se o principal produto de venda do agroextrativismo no Vale do Rio Urucuia. O preço aumentou significativamente, de uma média de $\mathrm{R} \$ 15,00$ o quilo da castanha em 2013, para $\mathrm{R} \$ 25,00 \mathrm{em} 2018$. Com isso, houve uma mudança no cenário da cadeia produtiva e no mercado, tendo em vista que muitos agroextrativistas especializaram-se somente na coleta desse fruto e abandonaram a de outros. Começaram, então, as disputas pelos locais de coleta, o que não foi registrado na pesquisa anterior (BISPO, 2014). Os fazendeiros que antes permitiam a coleta de baru gratuitamente passaram a cobrar uma porcentagem dos frutos (a "meia") ou ainda começaram a proibir a entrada de agroextrativistas em suas propriedades por causa da destruição dos baruzeiros, uma vez que muitas pessoas quebravam os galhos e arrancavam os frutos antes de estarem maduros.

Outro fato que passou a ocorrer depois da popularização do baru foi o roubo de sacas. Há ainda outra situação nova na região, a ida de pessoas de outras cidades, principalmente do Distrito Federal, somente na época da coleta, para obtenção da "renda do baru".

Devido a pesquisas científicas sobre as propriedades nutritivas e medicinais do baru, o fruto popularizou-se. Os clientes da cooperativa modificaram-se, a organização tornou-se revendedora de castanhas para grandes empresas, como a Mãe Terra, que foi adquirida pela multinacional Unilever, e a Barukas, uma empresa americana de alimentos saudáveis que importou 110 toneladas do fruto em 2018.

O baru tornou-se um fruto tão valorizado que a Fundação Slow Food para a Biodiversidade implantou a Fortaleza do Baru do Urucuia Grande Sertão, na cidade de Arinos, em maio de 2017. De acordo com o Slow Food Brasil (2007), "fortalezas são projetos concretos de desenvolvimento da qualidade dos produtos nos territórios, envolvendo diretamente os pequenos produtores, técnicos e entidades locais". Essas fortalezas envolvem produtores artesanais e buscam mercados alternativos para seus produtos. A referida Fortaleza tem a participação da Fundação Slow Food para a Biodiversidade, da Central do Cerrados (federação de cooperativas e de organizações de economia solidária instaladas em regiões de Cerrado e Caatinga) e da Copabase (cooperativa local do Vale do Rio Urucuia). Essa ação é importante para a promoção do baru da região, mas também para a busca de um comércio justo, produtos com qualidade e conservação da natureza.

A cadeia produtiva do baru é muito extensa e conta com várias etapas, pessoas e organizações (Figura $1^{4}$ ). Participam os agroextrativistas que coletam os frutos e os beneficiam, os atravessadores, a cooperativa, a empresa internacional, os compradores das feiras e o consumidor final, além das ações de organizações, como o Slow Food.

\footnotetext{
${ }^{4}$ Somente o baru teve sua cadeia produtiva demonstrada graficamente devido à complexidade da cadeia produtiva e a quantidade de organizações e instituições envolvidas na produção e comercialização do fruto.
} 


\section{Figura 1: Cadeia produtiva do Baru}

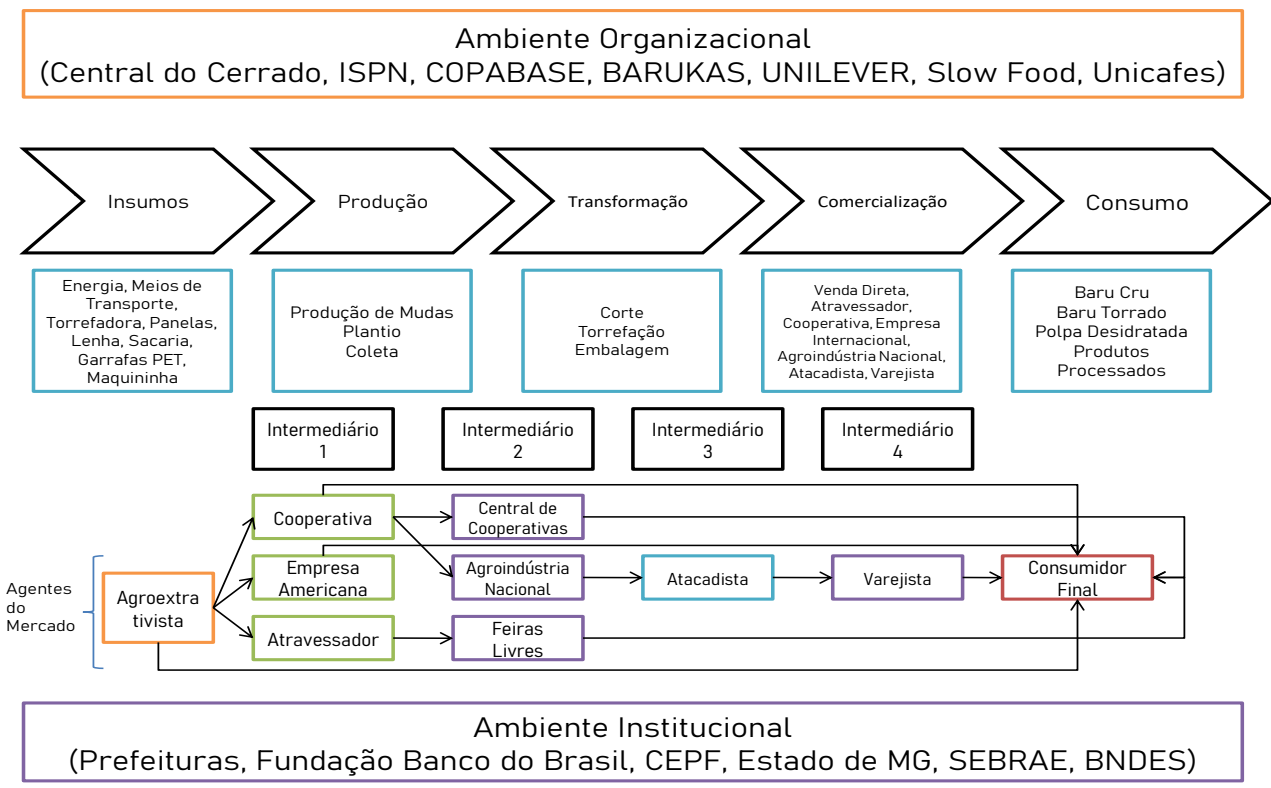

Fonte: elaborada pelos autores.

A presença da cooperativa de agroextrativistas no Vale do Rio Urucuia é vista como o diferencial para o desenvolvimento do mercado do baru na região. Essa organização foi responsável pela popularização do produto, bem como pela revisão de preços e quantidades. Inclusive, a empresa estrangeira chegou à região atraída por um mercado que já era organizado e, por isso, ali se estabeleceu.

O mercado do baru possui diversas configurações. O agroextrativista vende diretamente para o consumidor final, para os atravessadores, para a cooperativa e para a empresa americana. A decisão da escolha do comprador pelo agroextrativista é direcionada principalmente pelo preço de compra. A cooperativa, por ser uma organização formal, vende com nota fiscal e acessa mercados mais estruturados. É fornecedora de uma agroindústria nacional, por meio de contrato anual de venda e participa de federação ou central e de cooperativas que atua em toda a área do bioma Cerrado, além de eventuais atacadistas de castanhas. Para o consumidor final, a venda é feita no ponto comercial da cooperativa e em feiras e eventos de que esta participa.

Com a entrada das empresas de maior porte no mercado do baru, a cooperativa local, juntamente com membros da Fundação Slow Food para a Biodiversidade, tem buscado a manutenção da identidade do baru como um produto natural, orgânico, produzido por famílias de agroextrativistas familiares que têm mudado de vida, por meio do aproveitamento dos frutos nativos. As empresas que compram o baru trabalham o marketing do fruto com base na noção de alimento saudável, não vinculando a castanha aos produtores, mas sim a uma vida fitness.

\subsection{PEQUI: DE NORTE A SUL DO CERRADO}

O pequi tem como nome científico Caryocar brasiliense, essa é a espécie mais comum, mas existem outras. A família Caryocaraceae é formada por vinte e seis espécies distribuídas em dois gêneros, Caryocar e Anthodiscus (MARTINS; GRIBEL, 2007). De acordo com Kerr, Silva e Tchucarramae (2007), Caryocar é formada pelo grego Karyon (noz, núcleo) mais caro (carne). O nome pequi vem da língua indígena tupi, na qual py significa pele e qui espinhos. A palavra denota que o fruto tem uma pele, uma polpa e depois uma camada de pequenos espinhos. É uma planta de ocorrência em praticamente toda a extensão do Cerrado, por isso também é um dos frutos nativos mais consumidos em todo o bioma (OLIVEIRA; SCARIOT, 
2010). O pequi tem outros nomes populares, como piqui, pequiá, piquiá, piquiá-bravo, pequiábravo, amêndoa de espinho, grão de cavalo, pequerim e suari (PERES, S/D).

Além de estar presente na alimentação humana, o pequi faz parte da alimentação de diversos animais. O pólen das flores é fonte de alimento para morcegos e pássaros, que também contribuem para a polinização da planta. As flores, quando caem no chão, são consumidas por cotias, pacas, veados e tatus. Quanto aos frutos, fazem parte da cadeia alimentar de emas, seriemas, gralhas, pacas, cotias, veados e uma grande variedade de insetos (OLIVEIRA; SCARIOT, 2010).

O pequi também possui propriedades medicinais, dentre elas a cicatrização (BEZERRA; BARROS; COELHO, 2015). Além disso, comunidades utilizam o óleo para o tratamento contra gripe, febre, infecções bronco-pulmonar e como diurético (OLIVEIRA JÚNIOR; CONCEIÇÃO, 2010). Almeida et al. (2009) ressaltam que, no período entre os anos de $1982 \mathrm{e}$ 2005, o pequi foi um dos únicos produtos florestais não madeireiros que tiveram aumento de demanda, deixando de ser um produto regional para se tornar um produto nacional.

Nas pesquisas realizadas para esse artigo, tanto em Minas Gerais quanto no Maranhão, o pequi ficou caracterizado como um dos frutos mais conhecidos e consumidos pelos entrevistados, sendo representado como um fruto símbolo do Cerrado.

O pequi da região Sul Maranhense diferencia-se do pequi mineiro, por possuir o dobro do tamanho e uma maior quantidade de polpa. Em razão do local de ocorrência, o qual faz parte da área de transição do bioma Cerrado com o bioma Amazônia, trata-se de outra espécie da família Caryocaraceae, no caso o piquiá (Caryocar villosum (Aubl.) Pers. Caryocaraceae). Embora no Sul Maranhense os agroextrativistas chamem o fruto de pequi, todas as características da planta (entre 20 e 30 metros de altura, folhas lisas, tronco reto, frutos grandes) são do piquiá de ocorrência amazônica (MARTINS; GRIBEL, 2007).

A cadeia produtiva e o mercado do pequi nas duas regiões examinadas são similares. Existem dois produtos principais: o fruto inteiro com casca e o caroço. O beneficiamento desse fruto, geralmente, fica a cargo do consumidor final. No sul do Maranhão, além do processamento mínimo do fruto para comercialização no Programa de Compras da Agricultura Familiar (PROCAF) ${ }^{5}$, existe a produção do óleo da polpa do pequi, de modo que a principal destinação desse óleo é a fabricação artesanal de sabão. O sabão de pequi é utilizado pelos próprios agroextrativistas, o que caracteriza uma venda mínima desse produto. Para o mercado externo, os frutos são encomendados pelos atravessadores e, posteriormente, coletados e vendidos ainda na casca pelos agroextrativistas. Em seguida, o intermediário estipula o valor do milheiro de pequi coletado. Por fim, a carga é levada em caminhões para os destinos de consumo final.

O pequi mineiro tende a ser consumido localmente, participando de pratos tradicionais, como arroz com pequi e frango com pequi, mas também é direcionado para o mercado do Distrito Federal. O pequi destinado ao mercado externo é comprado pelos atravessadores ainda nas árvores, os quais adquirem a produção inteira de fazendas e, com os ajudantes, fazem a coleta e o transporte dos frutos. Não foi relatada venda de frutos já coletados por parte dos agroextrativistas locais. A coleta de frutos verdes, impróprios para o consumo, é uma prática comum por parte dos atravessadores, que buscam obter a maior quantidade do recurso, sem pensar na reprodução da planta nem nos outros animais que dela dependem. Posteriormente, o pequi é vendido em feiras ou no comércio informal das cidades do Distrito Federal.

\footnotetext{
${ }^{5}$ O governo do Maranhão criou, por meio da Lei no 10327, de 28/09/2015, o Programa de Compras da Agricultura Familiar (PROCAF), oriundo do Fundo Maranhense de Combate à Pobreza (FUMACOP), que tem por objetivo a aquisição direta de produtos agropecuários e extrativistas (in natura ou manufaturados) e de artesanato, produzidos tanto por agricultores familiares quanto por organizações sociais rurais e urbanas, bem como por povos e comunidades tradicionais e pelos beneficiários da reforma agrária.
} 
No Vale do Rio Urucuia, uma grande parte dos pequizais foi derrubada para ter sua madeira transformada em carvão e agora os pés são ameaçados pela substituição do Cerrado por plantios de grãos. No Sul Maranhense, os pequizais estão diminuindo, por causa da derrubada de grandes áreas de vegetação de chapada para o plantio de grãos. Além disso, entre os entrevistados, houve o relato de uma praga/doença que começa pela raiz das árvores e as leva à morte. Também foi dito que a produtividade dos pés de pequi tem diminuído a cada ano.

Embora o pequi seja um fruto muito popular, seus pés estão sendo derrubados indiscriminadamente. Essa prática prejudica a coleta pelos agroextrativistas, que, nesse caso, além da comercialização do produto, também consomem o fruto, o que contribui para a melhoria nutricional das famílias. Além disso, toda a função ambiental que as árvores, os frutos e as flores de pequi possuem é afetada. $\mathrm{O}$ incentivo à atividade extrativa implica na manutenção das áreas de floresta em pé, demonstrando sua importância para a preservação do Cerrado e manutenção dos modos de vida das famílias.

\subsection{BACURI: O FRUTO SÍMBOLO DO EXTRATIVISMO DO SUL MARANHENSE}

O bacuri (Platonia insignis) é um produto típico do extrativismo do Maranhão. Original da Amazônia Oriental, é uma árvore de médio a grande porte, da qual podem ser aproveitados a madeira e os frutos. Tem importância econômica nos estados do Maranhão, do Pará, do Piauí e do Tocantins, sendo o Pará o principal produtor e consumidor do fruto e da polpa de bacuri. As áreas de maior ocorrência sofrem uma forte ocupação humana, o que afeta a existência dessa planta no futuro. $\mathrm{O}$ bacuri possui grandes possibilidades de mercado e de geração de renda e pode ser utilizado na regeneração de áreas degradadas (MENEZES et al., 2011). Ressalta-se que a produção e o mercado do bacuri são localizados no Sul Maranhense. Na região do Vale do Rio Urucuia, em Minas Gerais, não há ocorrência natural do bacuri. Segundo Homma (2005), existe um crescimento de mercado para esse fruto, portanto aponta-se para a necessidade de aumento de área plantada.

Homma (2008) afirma que grande parte dos bacurizeiros foi derrubada no passado para obtenção de madeira. Atualmente, no Maranhão e no Piauí, o processo continua para a substituição das áreas pelo plantio de soja e abacaxi. Já no Pará, a espécie é substituída por roçados na ilha de Marajó, produção de lenha, feijão caupi (Vigna unguiculata), entre outros fatores. Para o autor, existem duas formas de ampliar a oferta do bacuri no mercado: a primeira é por meio de plantios racionais em áreas de recuperação de desmatamento, e a segunda é mediante manejo com a manutenção de uma floresta oligárquica. ${ }^{6}$ Esta última opção é mais interessante em curto prazo e pode ser direcionada aos agricultores familiares.

Menezes, Homma e Schöffel (2012) identificaram três tipos de sistema de exploração do bacuri nas mesorregiões do Nordeste Paraense e da Ilha do Marajó: o extrativo, o manejado e o plantado. O sistema extrativo é a fonte principal dos frutos, contudo essas árvores nativas ficaram mais escassas, devido à derrubada para a obtenção de madeira, o que mudou nos anos 2000, quando a extração da madeira foi substituída pela obtenção da polpa do fruto. O sistema manejado caracteriza-se pela recuperação de plantas advindas de brotações espontâneas, formadas entre 20 e 50 anos em roçados antigos, representada pela regeneração da vegetação secundária. O sistema plantado, que ainda é inicial, consiste no plantio de mudas de sementes e de enxertia. As mudas têm sido plantadas em áreas de sistemas agroflorestais, juntamente com o cultivo de pimenta-do-reino (Piper nigrum) e cacau (Theobroma cacao). O município de Tomé-Açu tem a maior área de bacurizeiros cultivados do Pará. Tanto os agricultores brasileiros quanto os de origem japonesa estão cultivando o fruto, incentivados pelo aumento da demanda da polpa.

\footnotetext{
${ }^{6}$ Floresta oligárquica é uma formação com número reduzido de espécies (GAMA et al., 2007).
} 
As principais técnicas utilizadas para manejo e cultivo do bacuri vêm do conhecimento empírico dos agricultores, que desenvolveram práticas próprias, em virtude da falta de assistência técnica e por existirem poucas pesquisas sobre a espécie (MENEZES; HOMMA; SHÖFFEL, 2012).

Menezes et al. (2011), em pesquisa no Nordeste Paraense, concluíram que a comercialização dos frutos e da polpa de bacuri é desorganizada e que os principais agentes de comercialização são os atravessadores. Estes compram dos coletores e comercializam na Central Estadual de Abastecimento (CEASA), em sorveterias e em mercados locais. Os autores observaram que a comercialização do bacuri é importante para os agricultores, pois gera recursos financeiros para compra de produtos básicos, como açúcar, café, óleo etc. Em razão de ser um produto que garante renda, existe um extrativismo predatório, com coleta de frutos verdes, quebra de árvores e invasão de propriedades para a coleta.

De forma semelhante, identificou-se que, no município de Carolina, há um comércio estabelecido de bacuri, existe primeiro um mapeamento da produção pelos atravessadores, assim, eles sabem se haverá produção suficiente. Posteriormente, são contratados atores locais para a coleta e despolpa dos frutos (grupos de pessoas, na maioria mulheres, em casas, na sede do município de Carolina, que utilizam tesouras para retirar a polpa "bruta" do fruto) e são comprados frutos e polpa minimamente processada dos agroextrativistas da região. Essas polpas são congeladas e ficam à espera de um caminhão refrigerado, o qual busca toda a produção que é levada para as capitais do Piauí, do Maranhão ou do Pará.

Observou-se que a cadeia agroindustrial do bacuri produz grande ocupação informal na época da sua coleta, em que jovens e adultos no meio rural coletam o fruto e vendem o milheiro, depois as pessoas que despolpam o fruto também têm um ganho de renda. Porém, em Carolina, toda a comercialização e a ocupação advinda do bacuri são conduzidas localmente pelos atravessadores, que agem de acordo com as encomendas das agroindústrias piauienses, maranhenses ou paraenses.

A movimentação subjacente do bacuri tem um motivo maior. Dentre os frutos citados pelos entrevistados do Sul Maranhense, é o que possui o preço mais alto, então as pessoas dos municípios onde existe a coleta desse fruto preferem comprar as demais polpas, por exemplo, a de cajá. A demanda de outras cidades é muito grande, tanto que faz os atravessadores buscarem o fruto em locais de difícil acesso na zona rural dos municípios. Interessante é que os agroextrativistas informaram que não há grande consumo de bacuri dentro dos municípios, já que a coleta é direcionada para o mercado regional de outras cidades e outros estados. Segundo os entrevistados, isso é devido ao preço mais elevado do fruto, o que faz com que a maior parte da população local não consiga comprá-lo, logo os preços pagos pelos atravessadores tornamse mais atrativos para os agroextrativistas. Também afirmaram que há certo preconceito em relação ao consumo do fruto, pois muitas pessoas dessas cidades acreditam que ele é "remoso", ou seja, faz mal à saúde para pessoas debilitadas, convalescentes de pós-operatório ou sensíveis a alergias. Não é aconselhado o consumo do fruto quente, com leite ou ovo, devido ao risco de mal-estar referido em algumas entrevistas. Além disso, observou-se que, em todos os estabelecimentos visitados, como restaurantes, hotéis e lanchonetes, não há suco de bacuri nos cardápios; apenas em uma sorveteria foi encontrado sorvete desse sabor.

Na cidade de São Raimundo das Mangabeiras, o bacuri não é muito comercializado. Os entrevistados afirmaram que os bacurizais estão cada vez mais escassos, devido ao desmatamento das chapadas (locais de ocorrência natural do bacuri) em função do plantio de grãos, majoritariamente soja. Então, os locais onde era feita a coleta dos frutos, com o decorrer dos anos de ocupação, estão deixando de existir. Mas o comércio do fruto, quando há, também é realizado por meio de atravessadores. Devido ao preço elevado, a cooperativa local não compra, acredita que é mais rentável para o agricultor vender diretamente para o atravessador. 
Confirmando o que Homma (2008) relata, na região do Sul Maranhense, para continuar com o comércio de bacuri, será necessário fazer plantios da espécie. A proposta do autor é o reflorestamento de áreas degradadas ou a recuperação de áreas de proteção permanente e de reservas florestais nas propriedades. Muitas pessoas obtêm uma parte importante da renda anual por meio do bacuri. Portanto, são necessárias ações emergenciais para a garantia do fruto a longo prazo.

A cadeia produtiva do bacuri é simples. Não existem muitos produtos processados advindos do fruto. O principal problema é o fator higiene. Não existe uma agroindústria ou locais apropriados para o corte. São utilizados galpões improvisados e áreas externas das casas dos agroextrativistas.

Já o mercado é coordenado pela agroindústria processadora de polpas de frutas. Mesmo distante, é ela quem dita preços e quantidades que devem ser negociados nos municípios. $\mathrm{O}$ bacuri participa de um mercado que possui um circuito longo de comercialização até sua chegada ao consumidor final, podendo ter até três intermediários. Isso faz com que o preço do produto fique diluído no mercado, e o maior prejudicado é o agroextrativista, tendo em vista que o trabalho de coleta, algumas vezes de processamento primário, é dele. A despeito disso, é esse agente que tem a menor participação nos ganhos do mercado. As vendas diretas, que vão para o consumidor final e para pousadas/hotéis, são de volume reduzido. Apenas um entrevistado, dentre os quinze agroextrativistas do Sul Maranhense, afirmou que faz vendas frequentes para esses estabelecimentos.

Se não existisse esse mercado para outros estados, o bacuri seria desperdiçado na região, ou seja, a maior parte viraria comida para gado bovino. Outra possibilidade seria a derrubada de árvores para o aproveitamento da madeira.

O mercado de bacuri é mais significativo em Carolina do que em São Raimundo das Mangabeiras. No segundo município, a presença do fruto é mais escassa, porque a vegetação é mais seca e parte dos poucos pés que existiam foi derrubada para plantio comercial de grãos.

\subsection{CAJÁ: O FRUTO APRECIADO DO NORDESTE}

O cajá (Spondias mombin L.) é uma espécie encontrada no Norte e no Nordeste brasileiro. $\mathrm{O}$ fruto tem nomes diferentes, podendo ser conhecido como cajá, cajá verdadeiro, cajá mirim e taperebá. O comércio dessa fruta tem crescido na região Nordeste, tanto a fruta fresca quanto a processada. A sua polpa tem sido matéria-prima de sucos, picolés, sorvetes, néctares e geleias. Em virtude do aumento da demanda de frutos de cajá, o interesse pelo cultivo também tem crescido, mas é uma planta que ainda está em processo de domesticação, e não há muitas informações sobre plantio de pomares comerciais (SOARES et al., 2006).

O cajá é consumido e cultivado no Brasil desde o tempo colonial. É um fruto aromático, rico em carotenoides, que o fazem ser amarelo, além da função nutritiva da substância. Possui também muitos taninos, daí o provável benefício de antioxidante natural (MATTIETTO; LOPES; MENEZES, 2010).

Verificou-se, em campo, que existe um grande consumo e comércio local de cajá, principalmente em restaurantes, lanchonetes, pousadas e hotéis. A procura pelo fruto é tão alta que até mesmo aqueles que são cultivados nos quintais das residências urbanas são comercializados. Na verdade, conforme os achados da pesquisa, a origem do fruto são justamente os quintais das moradias urbanas, bem como os cajazeiros nativos e os cultivados em propriedades rurais. Além da comercialização para abastecer o mercado local, a polpa é vendida para os mercados institucionais via Programa Nacional de Alimentação Escolar (PNAE) e Programa de Aquisição de Alimentos (PAA).

O cajá também é bastante comercializado em São Raimundo das Mangabeiras. O comércio é informal, uma vez que os próprios agroextrativistas processam e comercializam a 
polpa congelada por conta própria. A cooperativa local compra o fruto para o processamento e posterior venda para o PNAE, além da comercialização em um ponto de venda próprio.

Foi relatado por entrevistados que, antes do início da comercialização do fruto, não existia o consumo pela comunidade rural. As pessoas derrubavam ou colocavam fogo para a transformação da área em cultivo agrícola, a chamada "roça de toco". Depois da procura comercial, houve uma conscientização por parte dos coletores, que passaram a capinar em torno dos pés de cajá, preservar os espécimes nativos e plantar mudas.

Não são fabricados muitos derivados do cajá. Ele é um fruto que pode ser consumido in natura ou processado na forma de sucos ou picolés. A propósito, a Kibon, marca da Unilever, vende picolés com a propaganda de ser um fruto nativo do Brasil. Porém, entre os entrevistados e em suas organizações, o único produto processado é a polpa para suco. Três informantes possuem despolpadoras em suas residências e comercializam polpas congeladas diretamente ao consumidor final e para sacolões, que são pequenos mercados locais.

Não foram identificados atravessadores que fizessem parte do mercado do cajá, provavelmente devido à baixa oferta do produto para comercialização, já que está voltado predominantemente ao consumo local e aos mercados institucionais. Existiu, por alguns anos, no município de Carolina, uma empresa que comprava frutos que não possuíam mercado na região, como o próprio cajá, a cagaita, o araticum, entre outros de origem nativa, além de frutas comuns, como a acerola, a goiaba e o caju.

O cajá pode ser visto como um alimento que contribui para a melhoria nutricional dos agroextrativistas e da população local, pois é bastante consumido. Mas nem sempre participou da alimentação da população em geral, ou seja, não é um alimento tradicional na região estudada. Assim como no caso do bacuri, também existe certo preconceito em relação ao cajá. A população local, principalmente rural, faz uma distinção entre os alimentos nativos e os cultivados. Os nativos entram no grupo dos alimentos que são para animais ou de pessoas que não podem produzir seu próprio alimento. Já os cultivados são considerados importantes e recomendados para alimentação.

O aumento do consumo do cajá na região está associado à ação das organizações sociais na esfera local, como cooperativas, associações, empresas e Organizações Não Governamentais (ONGs). Por meio de cursos, capacitações e palestras, as instituições demonstraram a importância do uso dos frutos na melhoria da qualidade da alimentação.

\section{CONCLUSÃO}

De modo geral, a revisão bibliográfica e a experiência de campo demonstraram o potencial de diferentes frutos nativos do Cerrado do Brasil de regiões do Maranhão e Minas Gerais. Comprovou-se a relevância da cadeia produtiva, compreendendo que quanto mais organizada e estruturada estiver a cadeia, maiores serão os benefícios aos agroextrativistas, influenciando positivamente na qualidade de vida desse segmento e contribuindo para o desenvolvimento rural local.

Os frutos nativos que possuem cadeias produtivas mais organizadas são aqueles comercializados por cooperativas. Os demais participam dos mercados informais por meio da venda direta do agroextrativista ao consumidor final, mediante encomenda, venda de porta em porta, feiras, beira de estradas e mercados institucionais (PAA, PNAE e PROCAF). Esses frutos que não têm cadeias produtivas muito bem estruturadas também são os que mais possuem intermediários. Apontam-se como exemplos a forte participação dos atravessadores na comercialização do pequi e do bacuri e o certo nível de dependência dos extrativistas do cajá diante de programas de compras públicas.

Quanto mais organizada está a cadeia, mais o produto se torna atraente para empresas que não fazem parte de mercados alternativos, como no caso do baru em Minas Gerais. Toda a

IGepec, Toledo, V.25, p.133-152, 2021. Edição Especial:58 Congresso da SOBER 
cadeia produtiva foi organizada inicialmente pela cooperativa local, desde a organização da coleta, do preço, da logística de transporte e armazenagem, até o processamento padronizado da castanha desse fruto. Assim, com todo o ambiente organizado, uma empresa estrangeira se instalou no local e colocou o baru no mercado nacional e internacional.

O fator chave para a melhoria da comercialização e, consequentemente, da qualidade de vida dos agroextrativistas é a organização da cadeia produtiva. Isso abrange a qualidade da matéria-prima, a melhoria da logística e do processamento dos frutos nativos e a maior interação dos agroextrativistas ao longo das cadeias.

A presença do intermediário pode trazer benefícios por um lado, mas prejuízos por outro. Algumas das vantagens identificadas são: a possibilidade de escoamento da produção; o acesso aos mercados mais distantes; e a possível negociação de preços, quando há concorrência entre os intermediários. Em contrapartida, os prejuízos são: a diminuição da participação dos agroextrativistas no preço final do produto comercializado; a dependência de um único canal de comercialização; e a subordinação total às regras estabelecidas pelo atravessador. Destarte, para cada cadeia produtiva, faz-se necessária uma análise específica em relação à presença dos intermediários.

Há uma forte dependência de compras públicas para a manutenção das cadeias produtivas do agroextrativismo, principalmente por parte de cooperativas e associações, que direcionam as vendas e os padrões de produtos para os mercados institucionais, como o PNAE, o PAA e o PROCAF. Os produtos que conseguem ter uma diferenciação dos demais são o bacuri e o baru, por serem muito valorizados no mercado comum e terem preços elevados, se comparados aos demais.

Nas áreas de Cerrado estudadas, a maioria dos agroextrativistas não tinha um vínculo muito grande com a vegetação nativa, nem consumia grande parte dos frutos disponíveis na natureza, seja porque eram considerados frutos para alimentação de animais, seja porque recebem o estigma de venenosos ou danosos à saúde humana em geral.

Outro aspecto a ser destacado refere-se à relação entre preservação ambiental e agroextrativismo, já que a atividade depende da conservação das florestas. Observou-se que, quando realizada a extração de frutos nativos, existe um esforço de manutenção de áreas de floresta e consequente salvaguarda dos recursos naturais. Porém, não se trata de algo implícito à atividade. Conforme esclarecido no caso do Baru, os próprios extrativistas podem agir em direção a uma exploração predatória, exaurindo os recursos disponíveis em detrimento de maiores rendimentos. Além disso, destacam-se as consequências da expansão de áreas agrícolas por meio do plantio de grãos nas regiões, o que coloca os agricultores familiares em uma situação de insegurança, afeta diretamente a reprodução social e econômica das famílias e causa sérios impactos ambientais no Cerrado. 


\section{REFERÊNCIAS}

ABRANTES, J.S. Bio(sócio)diversidade e empreendedorismo ambiental na Amazônia. Rio de Janeiro: Garamond, 2002.

ALMEIDA, A. N.; BITTENCOURT, A. M.; SANTOS, A.J.; EISFELS, C. L.; SOUZA, V. S. Evolução da produção e preço dos principais produtos florestais não madeireiros extrativos do Brasil. CERNE, [S.l.], v. 15, n. 3, p. 282-287, jul.-set. 2009.

ARNOLD, J.E.M.; PEREZ, M.R. Can non-timber forest products match tropical forest conservation and development objectives? Ecological Economics, [S.l.], 39, p. 437-447, 2001.

BATALHA, M.O. As cadeias de produção agroindustriais: uma perspectiva para o estudo das inovações tecnológicas. Revista de Administração, São Paulo, v. 30, n. 4, p. 43-50, out.-dez. 1995.

BEGNIS, H.S.M.; ESTIVALETE, V.F.B.; PEDROZO, E.A. Confiança, comportamento oportunista e quebra de contratos na cadeia produtiva do fumo no sul do Brasil. Gestão e Produção, São Carlos, v. 14, n. 2, p. 311-322, maio-ago. 2007.

BEZERRA, N.K.M.S.; BARROS, T.L.; COELHO, N.P.M.F. A ação do óleo de pequi (Caryocar brasiliense) no processo cicatricial de lesões cutâneas em ratos. Revista Brasileira de Plantas Medicinais, Campinas, v. 17, n. 4, supl. II, p. 875-880, 2015.

BISPO, T.W. A transformação do agroextrativismo do Cerrado: casos do Sul Maranhense e do Vale do rio Urucuia em Minas Gerais - Brasil. 2020. 229 f. Tese (Doutorado em Desenvolvimento Sustentável) - Centro de Desenvolvimento Sustentável, Universidade de Brasília, Brasília, 2020.

BISPO, T.W. Agroextrativismo no vale do Rio Urucuia - Minas Gerais: formas de organização da produção e da distribuição. 2014. 146 f. Dissertação (Mestrado em Agronegócio) - Faculdade de Agronomia e Veterinária, Universidade de Brasília, Brasília, 2014.

BRASIL. Ministério da Agricultura, Pecuária e Abastecimento; Ministério do Meio Ambiente. Instrução Normativa Conjunta n. 17, de 28 de maio de 2009. Aprovar as normas técnicas para a obtenção de produtos orgânicos oriundos do extrativismo sustentável orgânico.. Ministério da Agricultura, Pecuária e Abastecimento; Ministério do Meio Ambiente: Brasília, 2009.

BRASIL. Lei n. 11.326, de 24 de julho de 2006. Estabelece as diretrizes para a formulação da Política Nacional da Agricultura Familiar e Empreendimentos Familiares Rurais. Brasília, 2006. 
CARRAZZA, L. R. Tecnologias sociais agroextrativistas como estratégia de conservação ambiental e desenvolvimento local. In: OTTERLOO, A. (Org.) Tecnologias sociais: caminhos para a sustentabilidade. Brasília: Brasil, 2009. p. 265-277.

CASTRO, A.M.G.; LIMA, S.M.V.; CRISTO, C.M.P.N. Cadeia produtiva: marco conceitual para apoiar a prospecção tecnológica. In: Simpósio Gestão da Inovação Tecnológica, 22, 2002, Salvador. Anais... Salvador: 2002.

DUTRA, R. M.S.; SOUZA, M. M. O. Agroextrativismo e geopolítica da natureza: alternativa para o Cerrado na perspectiva analítica da cienciometria. Ateliê Geográfico, Goiânia, v. 11, n. 3, p. 110-133, dez. 2017.

FORZZA, R.C.; BAUMGRATZ, J.F.A.; BICUDO, C.E.M.; CANHOS, D.A.L.; CARVALHO JR, A.A.; COSTA, A.; COSTA, D.P.; HOPKINS, M.; LEITMAN, P.M.; LOHMANN, L.G.; LUGHADHA, E.N.; MAIA, L.C.; MARTINELLI, G.; MENEZES, M.; MORIM, M.P.; COELHO, M.A.N.; PEIXOTO, A.L.; PIRANI, J.R.; PRADO, J.; QUEIROZ, L.P.; SOUZA, S.; SOUZA, V.C.; STEHMANN, J.R.; SYLVESTRE, L.S.; WALTER, B.M.T.; ZAPPI, D. Síntese da diversidade brasileira. In: FORZZA, R.C.; LEITMAN, P.M.; COSTA, A.; CARVALHO JR, A.A.; PEIXOTO, A.L.; WALTER, B.M.T.; BICUDO, C.; ZAPPI, D.; COSTA, D.P.; LLERAS, E.; MATINELLI, G.; LIMA, H.C.; PRADO, J.; STEHMANN, J.R.; BAUMGRATZ, J.F.A.; PIRANI, J.R.; SYLVESTRE, L.S.; MAIA, L.C.; LOHMANN, L.G.; PAGANUCCI, L,. SILVEIRA, M.; NADRUZ, M.; MAMEDE, M.C.H.; BASTOS, M.N.C.; MORIM, M.P.; BARBOSA, M.R.; MENEZES, M.; HOPKINS, M.; SECCO, R.; CAVALCANTI, T.; SOUZA, V.C. Catálogo de plantas e fungos do Brasil. (Orgs.). Rio de Janeiro: Instituto de Pesquisas Jardim Botânico do Rio de Janeiro, 2010. Introdução. p.19-42.

GAMA, J. R. V.; SOUZA, A.L.; CALEGÁRIO, N.; LANA, G.C. Fitossociologia de duas fitocenoses de floresta ombrófila aberta no município de Codó, estado do Maranhão. Revista Árvore, Viçosa, v. 31, n. 3, p. 465-477, 2007.

GOMES, C.V.A. Ciclos econômicos do extrativismo na Amazônia na visão dos viajantes naturalistas. Boletim do Museu Paraense Emílio Goeldi, [S.l.], v. 13, n. 1, p. 129-146, jan.abr. 2018.

GRIFFON, M. Economie institutionnelle et agriculture. Montpellier: CIRAD-MES, 1994.

HOMMA, A.K.O. Extrativismo vegetal ou plantio: qual a opção para a Amazônia? Estudos Avançados, [S.l.], v. 26, n. 74, p. 167-186, 2012.

HOMMA, A.K.O. Extrativismo, biodiversidade e biopirataria na Amazônia. Embrapa Informação Tecnológica: Brasília, 2008.

HOMMA, A.K.O. Amazônia: como aproveitar os benefícios da destruição? Estudos Avançados, [S.l.], v. 19, n. 54, p. 115-135, 2005.

KERR, W.E.; SILVA, F.R.; TCHUCARRAMAE, B. Pequi (Caryocar brasiliense Camb.). Informações preliminares sobre um pequi sem espinhos no caroço. Revista Brasileira de Fruticultura, Jaboticabal, v. 29, n. 1, p. 169-171, 2007. 
KRAG, M.N.; SANTANA, A.C.; SALOMÃO, R.P.; MARTINS, C.M.; GOMES, S.C. A governança do arranjo produtivo local da castanha-do-brasil na região da Calha Norte, Pará. Revista de Economia e Sociologia Rural, Piracicaba, v. 55. n. 3, p. 589-608, jul.-set. 2017.

LANÇON, F.; TEMPLE, L.; BIÉNABE, E. The concept of filière or value chain: an analytical framework for development policies and strategies. In: BIÉNABE, E.; RIVAL, A.; LOEILLET, D. (Eds.) Sustainable development and tropical agri-chains. Dordrecht: Springer, 2017. p. 17-28.

MARTINS, R.L.; GRIBEL, R. Polinização de Caryocar villosum (Aubl.) Pers. (Caryocaraceae) uma árvore emergente da Amazônia Central. Revista Brasileira de Botânica, [S.l.], v. 30, n. 1, p. 37-45, jan.-mar. 2007.

MATTIETTO, R.A.; LOPES, A.S.; MENEZES, H.C. Caracterização física e físico-química dos frutos da cajazeira (Spondias mombin L.) e de suas polpas obtidas por dois tipos de extrator. Brazilian Journal of Food Technology, Campinas, v. 13, n. 3, p. 156-164, jul./set. 2010.

MENEZES, A.J.E.A.; HOMMA, A.K.O.; SHÖFFEL, E.R. Do extrativismo à domesticação: o caso do bacurizeiro no Nordeste Paraense e na Ilha do Marajó. Belém: Embrapa Amazônia Oriental, 2012.

MENEZES, A.J.E.A.; HOMMA, A.K.O.; SCHÖFFEL, E.R.; FILGUEIRAS, G.C. A comercialização do fruto de bacuri pela agricultura familiar no nordeste paraense e Ilha de Marajó no Pará. In: SOBER Nordeste, 6, 2011, Petrolina, Anais... Petrolina, 2011.

MORVAN, Y. Fondements d'économie industrielle. Paris: Economica, 1988.

MOTA, D.M.; SCHMITZ, H.; SILVA JÚNIOR, J.F.; RODRIGUES, R.F.A. O trabalho familiar extrativista sob a influência de políticas públicas. Revista de Economia e Sociologia Rural, Piracicaba, v. 52, s. 1, p. S189-S204, 2014.

NOGUEIRA, M.C.R.; FLEISCHER, S.R. Entre a tradição e modernidade: potenciais e contradições da cadeia produtiva agroextrativista no Cerrado. Estudos Sociedade e Agricultura, São Paulo, v. 13, n. 1, p. 125-157, 2005.

OLIVEIRA JÚNIOR, S.R.; CONCEIÇÃO, G.M. Espécies vegetais nativas do Cerrado utilizadas como medicinais pela comunidade Brejinhos, Caxias, Maranhão, Brasil. Cadernos de Geociências, [S.l.], v. 7, n. 2, p. 140-148, nov. 2010.

OLIVEIRA, W.L.; SCARIOT, A. Boas práticas de manejo para o extrativismo sustentável do pequi. Brasília: Embrapa Recursos Genéticos e Biotecnologia, 2010.

PERES, M.R. Pequi. $\quad$ Disponível em $<$ http://www.agencia.cnptia.embrapa.br/gestor/agroenergia/arvore/CONT000fbl23vmz02wx5 eo0sawqe3egcicvo.html>. Acesso em: 10 abr. 2019.

RAIKES, P.; JENSEN, M.F.; PONTE, S. Global commodity chain analysis and the French filière approach: comparison and critique. Economy and Society, [S.l.], v. 29, n. 3, p. 390417, 2000. 
RAVENA, N. ; MARIN, R.E.A. A teia de relações entre índios e missionários: a complementaridade vital entre o abastecimento e o extrativismo na dinâmica econômica da Amazônia Colonial. Varia História, Belo Horizonte, v. 29, n. 50, p. 395-420, mai.-ago. 2013.

ROCHA, L.S.; CARDOSO SANTIAGO, R.A. Implicações nutricionais e sensoriais da polpa e casca do baru (Dipteryx alata Vog.) na elaboração de pães. Ciência e Tecnologia de Alimentos, Campinas, v. 29, n. 4, p. 820-825, out.-dez. 2009.

SLOW FOOD BRASIL. Fortalezas. Disponível em:

<http://www.slowfoodbrasil.com/fortalezas>. Acesso em: 20 abr. 2019.

SOARES, E.B.; GOMES, R.L.F.; CARNEIRO, J.G.M.; NASCIMENTO, F.N.; SILVA, I.C.V.; COSTA, J.C.L. Caracterização física e química de frutos da cajazeira. Revista Brasileira de Fruticultura, Jaboticabal - SP, v.28, n.3, p.518-519, dez. 2006.

VERA, R.; SOUZA, E.R.B. Baru. Revista Brasileira de Fruticultura, Jaboticabal, v. 31, n. 1, mar. 2009.

Submetido em 29/11/202O

Aprovado em 20/12/2O2O

\section{Sobre os Autores:}

Tayline Walverde Bispo

Email: taylinewalverde91@gmail.com

Stéphane Guéneau

Email: stephane.gueneau@cirad.fr

Camila Lago Braga

Email: camila.lago.braga@gmail.com

Cristiane Cavalcante Lima

Email: cristiane.lima@ifam.edu.br 